\title{
Normative Alethic Pluralism
}

\author{
Filippo Ferrari
}

Universität Bonn

\section{Introduction}

Some philosophers have argued that truth is a norm of judgement. ${ }^{1}$ This thesis has been given in a variety of formulations - that true judgements are the correct ones; that it is better to judge truly than to judge falsely; and that the truth is what judges ought to pursue in enquiry. I will assume that truth somehow functions as a norm of judgement, and I will be focusing on two core questions concerning the judgement-truth norm-namely:

(i) what are the normative relationships between truth and judgement?

(ii) do these relationships vary or are they constant?

I argue for a pluralist picture-what I call normative alethic pluralism ${ }^{2}$ (henceforth NAP)— according to which (i) there is more than one correct judgement-truth norm and (ii) the normative relationships between truth and judgement vary in relation to the subject matter of the judgement. By means of a comparative analysis of disagreement in three core areas of the evaluative domain - refined aesthetics, basic taste and morality-I show that there is an important variability in the normative significance that disagreement has in these areas-I call this the variability conjecture. By presenting a variation of Lynch's scope problem for alethic monism, I argue that a monistic approach to truth's normative function is unable to vindicate

\footnotetext{
${ }^{1}$ For example: Dummett 1959, Gibbard 2005, Horwich 2013, Shah and Velleman 2005, Wedgwood 2007; Wright 1992.

${ }^{2}$ Since the label can be misleading in one important respect, I should clarify that with it I mean a pluralist account of the normative function that truth plays in relation to judgements. It is not part of the proposal to claim that this pluralist account requires or entails a pluralistic account of the nature of truth-although, the two views, taken together, gives a highly coherent and neat package.
} 
the normative variability conjecture. I then argue that normative alethic pluralism provides us with a very promising model to account for such a conjecture.

I leave the discussion of both the metaphysical issue of what grounds these normative relationships and the epistemic issue of what justifies our beliefs about them aside. In particular, I take no stand on the question of whether truth's normative function reflects a characteristic intrinsic to the nature of truth or whether it is grounded in some features external to truth's nature. I intend the framework developed here to be compatible with rejecting the thesis that truth is an intrinsically normative notion. ${ }^{3}$

\section{The Truth-Norm}

Advocates of the thesis that truth is a norm disagree about how the norm should be conceived, and many formulations of it have been given. The following list provides a sample of formulations that can be found in the recent debate (my emphases):

Horwich We ought to want our beliefs to be true (and therefore not-want to have any false ones). ${ }^{4}$

James The true is the name of whatever proves itself to be good in the way of belief. 5

Loewer True belief is valuable and, other things being equal, it is a rational doxastic policy to seek true beliefs. ${ }^{6}$

Lynch $\quad$ End of Inquiry: True propositions are those we should aim to believe when engaging in inquiry.

\footnotetext{
${ }^{3}$ See Ferrari (2016b) for an account of the normativity of truth — especially of what I call the axiological dimension of the normativity of truth (see below, section II) - which is compatible with the minimalist conception of truth advocated by Horwich (in, e.g., Horwich 1998).

${ }^{4}$ Horwich 2013: 17.

${ }^{5}$ James 1975: 42.

${ }^{6}$ Loewer 1993: 266.
} 
Norm of Belief: True propositions are those that are correct to believe. ${ }^{7}$

McHugh

Wedgwood

Williams
[T] he attitude of belief sets truth as the standard that a proposition must meet in order for it to be a fit object of that attitude. ${ }^{8}$

For any $\mathrm{S}$, $\mathrm{p}$ : If $\mathrm{S}$ considers whether $\mathrm{p}$, then $\mathrm{S}$ ought to believe that $\mathrm{p}$ if and only if $\mathrm{p}$ is true. ${ }^{9}$

Beliefs aim at truth. ${ }^{10}$

While philosophers in the list take the truth-norm to apply to belief, I take judgements to be the things that truth is primarily normative over. Following Shah and Velleman, I consider a judgement to be a cognitive mental act of affirming a proposition. It is a mental act because "it involves occurrently presenting a proposition, or putting it forward in the mind. It is a cognitive act because it involves presenting the proposition as true." ${ }^{11}$ In this respect judgements differ from beliefs, which are cognitive mental attitudes. The precise relationship between judgement and belief is a complex issue which won't concern us in this paper. ${ }^{12}$ Somewhat simplistically, I take it that the end product of a judgement is typically a belief whose content is a proposition. Since the examples I will consider involve an evaluative process, I take them to be fairly typical cases of beliefs formed through an act of judging. Thus, I use the expression 'norms governing judgement' as a catchall expression to indicate norms governing the formation, maintenance, and relinquishing of beliefs formed by means of an act of judging.

Two things about this list and the current debate on the judgement-truth norm deserve some discussion. The first concerns the variability in the use of the normative vocabulary involved in the formulations above. Some formulations employ terms like 'should' or 'ought' -

\footnotetext{
${ }^{7}$ Lynch 2013: 24.

${ }^{8}$ McHugh 2014: 177.

${ }^{9}$ Wedgwood 2007.

${ }^{10}$ Williams 1973: 136.

${ }^{11}$ Shah and Velleman 2005: 503.

${ }^{12}$ On this, see Chrisman 2016 and Sosa 2015, part III.
} 
thus using deontic terms; others involve notions such as 'valuable' and 'good' - thus using an axiological vocabulary; others still talk in terms of truth's being the aim of beliefs - using a teleological vocabulary; and, finally, others formulate the truth-norm in terms of correctness or fittingness - taking these notions to be normatively independent of any axiological or deontic element. I introduce the term criterial to indicate this latter category of normative notions. Mixed formulations - i.e. formulations mixing different normative vocabularies - are also possible, as Lynch's way of cashing out the normative role of truth both in terms of aim and in terms of correctness seems to suggest.

Abstracting from the many issues concerning the precise formulation and interpretation of the truth norm, we can capture the highlighted variability in the ways in which the norm is conceived by distinguishing the following normative dimensions: $:^{13}$

TELEOLOGICAL Judgement aims at truth.

CRITERIAL It is correct (fitting) to judge that $p$ (if and) only if $p$ is true.

AXIOLOGICAL It is valuable (good) to judge that $p$ (if and) only if $p$ is true.

DEONTIC One ought to judge that $\mathrm{p}$ (if and) only if $\mathrm{p}$ is true.

These are four distinct dimensions of the normative constraint that truth can exert on judgement. In section IX, I show that the criterial, the axiological, and the deontic dimensions of the normative role of truth are normatively independent of each other. What about the teleological dimension? I take it to be (partly) constitutive of the act of judging. In judging, a subject performs an act that aims, constitutively, at the truth of the subject matter at issue. This means that all judgements, as I understand them here, deal with truth-apt discourse. In this respect, the teleological dimension is always present whenever a proper judgement is performed and for this reason I leave this dimension aside in the discussion that follows.

\footnotetext{
${ }^{13}$ I focus on judgement rather than belief (as all the authors mentioned above do) to avoid intricate issues concerning the doxastic voluntarism versus non-voluntarism debate.
} 
With this in hand, I call a normative principle (NP) any principle expressing the normative constraint that truth exerts on judgement in terms of one or more of the three aforementioned dimensions - i.e. criterial, axiological, and deontic. The notion of a normative principle so defined allows for some flexibility. In this sense, all the various norms in the list above count as normative principles as I have defined the term.

The second thing worth mentioning is that the philosophers in the list above assumeat least implicitly, in the context of their work-that their preferred NP applies uniformly to all judgements regardless of their subject matter. In other words, they all seem to share a commitment to a monistic conception of the normative function of truth-what I call Normative Alethic Monism (NAM). Such a conception encompasses the following two theses:

Singularity: There is only one NP expressing truth's normative function on judgement. ${ }^{14}$ Uniformity: NP applies uniformly to all judgements in all areas of truth-apt discourse. I take singularity and uniformity to provide a characterisation of NAM in terms of jointly sufficient and individually necessary conditions. Moreover, singularity and uniformity are independent theses: one might deny uniformity but endorse singularity by maintaining that with respect to a specific set of judgements the truth-norm is normatively silent; ${ }^{15}$ or one might deny singularity but endorse uniformity by maintaining that truth uniformly exerts a plurality of normative functions for all judgements. However, neither of these ways of rejecting NAM amounts to what I take to be a genuine form of normative pluralism (more on this later).

To make NAM more perspicuous, let us consider two specific applications of it. First, say that an alethic deontologist is a philosopher who thinks that the unique normative alethic principle governing all judgements is deontic - i.e. it provides thinkers with some prescriptions about what to judge. An alethic deontologist, then, takes truth and falsity to always line up,

\footnotetext{
${ }^{14}$ Singularity resembles Williamson's simple account, but without the constitutivist element. See Williamson 2000: 240

${ }^{15}$ See Williams 2012 for an account of normative silence.
} 
respectively, with the obligatoriness and the impermissibility of the judgement in question. Second, those-alethic axiologists — who think of truth's normative function in purely axiological terms - i.e. in terms of what it is good or bad to believe - will take truth and falsity to always line up, respectively, with the good and the bad in the way of judgements.

NAM imposes a structural rigidity in the normative function of truth which, I argue, makes it unable to account for differences in the normative significance of disagreement.

\section{Disagreement and its Normative Significance}

By the expression 'normative significance of disagreement' I mean the extent to which engaging in a disagreement licenses participants to negatively evaluate each other's view. The kind of disagreement that matters for the purposes of this paper is something analogous to what MacFarlane calls the simple view of disagreement (i.e. doxastic noncotenability): ${ }^{16}$

DIS To disagree with someone's judgement that $\mathrm{p}$ is to issue judgements whose contents are jointly incompatible with $\mathrm{p} .{ }^{17}$

Disagreement, in the DIS model, is thus minimally normatively significant in the following way: a commitment to judging that $p$ is a commitment not only to the truth of $p$ but also to the falsity of every content $q$ which is incompatible with $p$, and consequently a commitment to assessing anybody endorsing $q$ as judging falsely. However, what other kinds of negative normative assessment or reactive attitude ${ }^{18}$ to a contrary view are associated with an attribution of falsity and thus licensed by the presence of a disagreement varies in relation to the subject matter at issue. Call this the variability conjecture.

\footnotetext{
${ }^{16}$ MacFarlane 2014: Chapter 6.

${ }^{17}$ Where 'incompatibility' here is understood in semantic terms, either as contrariness or contradictoriness of the propositional contents involved.

${ }^{18}$ In the sense discussed by Strawson 1962.
} 
With this in hand, let's now turn to a discussion of some examples. The examples I will consider involve evaluative judgements - i.e. judgements about evaluative matters such as basic taste, refined aesthetics and, more controversially, fundamental morality. ${ }^{19}$ These are judgements for which a substantive kind of objectivity may be hard to sustain and, for this reason, they are taken to lack robustly representational content - in the sense of Wright (1992, Ch.4). In this respect, these judgements are not subject to the possibility of a more fundamental kind of failure - a failure deriving from a misrepresentation of how things are objectively, i.e. in mind-independent reality.

Moreover, I should point out that these are just a few examples that I have chosen because I think they are particularly fit to show the kind of variability in the normative significance of disagreement I am interested in. Nothing hinges on which particular example we choose to highlight this variability. Also, I am not claiming that all examples of moral, aesthetic and taste disagreement should be understood in the way suggested. Perhaps there is also substantive intra-domain variability. This, though, wouldn't weaken my proposal— the more variability the better. However, in order to keep the discussion reasonably simple and smooth, I shall talk as if the three examples I discuss are paradigmatic of the three domains in question.

\section{Disagreement (1)—Fundamental Moral}

Consider the following disagreement about some fundamental moral value between Julie and Jill:

Julie thinks that torturing people is always a morally deplorable practice.

Jill disagrees, thinking that sometimes torturing people is after all morally acceptable.

\footnotetext{
${ }^{19}$ NAP can be integrated into a realist conception of morality and aesthetics and help in getting a handle on the difference in normative significance between these kinds of disagreement and disagreement about some other factual matters.
} 
I take this to be an example of some deep incompatibility between moral values concerning fundamental human rights. Thus, we may ask: what kind of normative assessment of Jill's contrary view would we typically expect from Julie in such a situation of disagreement? We would expect Julie to issue a strongly negative assessment of Jill's view. Not only would Julie think that Jill is completely wrong, but she would also feel compelled to think that Jill ought to change her mind about that issue. In fact, she would find it quite deplorable that Jill holds such a morally bad view.

What this suggests is that the kind of reaction we would expect from Julie amounts to a substantial criticism of Jill's contrary view, which, in some cases, leads to a disposition to urge Jill to revise her view on torture. Even assuming that Julie and Jill consider each other equally knowledgeable on most of the relevant non-moral facts concerning torture, once the disagreement comes to light they will typically cease to consider each other as equally respectable moral judges, at least with respect to a range of topics closely connected to the subject matter of their disagreement.

An appealing explanation of the appropriateness of this kind of substantive criticism of our opponent's moral standing might be linked to a distinctive feature of moral value - namely, what we might call the higher-order heritability of moral value. ${ }^{20}$ The thought is that the moral condemnation of a certain action or practice in these fundamental cases engenders a commitment to judging the holding of any view favourable to that action or practice as alethically impermissible. In this respect, strong moral criticism of a certain practice carries with it a strong alethic criticism of the holding of any judgement supporting that practice. The criticism is typically conveyed by means of an attribution of falsity to such a judgement, which, in this case, goes hand in hand with assessing the judgement as impermissible.

\footnotetext{
${ }^{20}$ This label has been suggested to me by Crispin Wright (personal conversation).
} 
That said, it is important to keep in mind that this is a reconstruction of what we might typically expect in a situation of disagreement about fundamental moral issues. In other words, this is merely a conjecture concerning the typicality of a certain pattern of response to a situation of disagreement in some radical cases of incompatibility of fundamental moral values. There certainly may be a variety of contextually salient factors that would impact on the kind of critical assessment that we would deem appropriate — but for the sake of simplicity I will leave these atypical cases aside.

\section{Disagreement (2)—Basic Taste}

Consider now a situation in which Julie and Jill have a dispute about basic taste. I here draw an intuitive distinction between judgements about matters of basic taste and judgements about matters of refined aesthetics. Without endorsing any controversial thesis about where to draw the boundary between basic taste and refined aesthetics — there might be no sharp boundary — I will discuss two examples that might be taken as paradigmatic of each category. Let's begin with the basic taste case:

\section{Julie thinks that oysters are delicious.}

\section{Jill disagrees, thinking that they are tasteless. ${ }^{21}$}

In sharp contrast to the fundamental moral case, the kind of negative assessment of Jill's contrary view we would typically expect from Julie would be paradigmatically weak —in fact nothing more than the realization that they have divergent views on the taste of some particular oysters, and this alongside with an appreciation, in typical circumstances, ${ }^{22}$ of the legitimacy

\footnotetext{
${ }^{21}$ I assume, contra contextualists and expressivists, that even in the case of basic taste we can make sense of disagreement in terms of doxastic noncotenability. Defending this claim would take me too far away-but see MacFarlane 2014 and Ferrari \& Wright 2017 for some arguments against a contextualist and expressivist treatment of basic taste judgements.

${ }^{22}$ Here by typical circumstances I mean circumstances in which no appreciable defeater-e.g. one of the party being under anaesthetics or her gustatory sensibility being temporarily impaired because of the effect of a strong cough syrup that alters her taste-is in place.
} 
of Jill's contrary view. If this approximates what people would typically expect in a situation of disagreement about basic taste, it shows that no substantive criticism of a contrary view should be expected. Absent pragmatic issues of coordination, ${ }^{23}$ a live and let live attitude is deemed appropriate. We may take as evidence of this that a rather natural follow-up that we might expect from Julie in coming to know about Jill's contrary view would be a first-person qualification of the judgement-e.g. "Oh, well, I just wanted to say that I like these oysters"${ }^{24}$ as a way of avoiding, in the dialectical context of the disagreement, the emergence of what might be considered an unjustified and futile quarrel. In fact, the mere presence of disagreement does not typically make either Jill or Julie less confident about her own opinion concerning oysters. What might happen sometimes is that, whenever it is plausible to assume a certain commonality of taste within the context of the disagreement, we experience a sense of surprise or curiosity in coming to know that someone we thought had a similar taste in fact has a radically different opinion about the food in question.

\section{Disagreement (3)—Refined Aesthetics}

Last, consider the following dialogue about a matter of refined aesthetics:

Julie thinks that Gould's 1955 execution of Goldberg Variations is unequalled.

Jill disagrees, thinking that the 1955 execution is too virtuosic. The 1981 version is preferable as a more mature interpretation.

What kind of negative assessment of someone's holding a contrary view should we expect in a disagreement about matters of refined aesthetics? Here it seems plausible to conjecture that the kind of critical reaction to Jill's contrary view that people would deem appropriate for Julie to have is one that falls somewhere in the middle of the two extremes of the fundamental moral

\footnotetext{
${ }^{23}$ E.g. a situation in which Julie and Jill have to decide whether to take their best friend to a French bistro.

${ }^{24}$ A discussion of this point can be found in Ferrari \& Wright 2017. Wyatt 2018, pp. 263-5 makes a similar prediction about first-person qualifications in cases of disagreement about basic taste.
} 
case and the basic taste case. Thus, we may typically expect Julie to be somehow surprised by Jill's contrary judgement regarding Gould's 1955 execution of Goldberg Variations. This is because she would think that Jill's judgement is somehow off-colour. Thus, a certain degree of criticism would be regarded as appropriate. In particular, it would be natural for Julie to consider Jill's aesthetic sensibility on this occasion to be not as good as her own. In this respect, contrary to the basic taste case, disagreement about refined aesthetics seems to give rise to an attribution of fault. Although it seems appropriate for Julie to continue to regard Jill as wellinformed as she is about Glenn Gould's musical production, by being committed to her own judgement about Gould and thus to her own scale of aesthetic value, she is committed to assessing Jill's opinion as inferior-indeed, one that it would be better not to have. As a result, it might happen that in some cases the conversation continues by each subject trying to persuade the opposite party to change her mind. However, in contrast with the fundamental moral case described above, the degree of intensity of the reactive attitude that would be appropriate for Julie to have in response to Jill's contrary view is significantly lower than in the fundamental moral case. We could certainly understand, if not justify, a high degree of heat in disputes about fundamental moral issues, but not in disputes about refined aesthetics. Regardless of how much aesthetically off-colour I consider your contrary view, granted that we are equally knowledgeable about the subject matter in question I would still feel some pressure to regard you as permitted to hold to the view you endorse. ${ }^{25}$

\section{Normative Alethic Monism and the Normative Scope Problem}

I will now argue that NAM falls prey to a serious objection that originates in a particular application of what is known in the truth pluralism debate as the scope problem for monistic (substantivist) conceptions of truth. The thought at the core of the objection is that no single

\footnotetext{
${ }^{25}$ See Ferrari 2016a for a more detailed discussion of the comparison between disagreement in basic taste and disagreement in refined aesthetics.
} 
substantive notion of truth-e.g. correspondence, superassertibility, or coherence-seems to be fully adequate to play the truth role across all different domains. ${ }^{26}$ For instance, whereas correspondence might be the adequate notion of truth for our judgements about the physical constitution of the world, it might score less well as the notion of truth for the domain of basic taste and other evaluative domains. Similarly, a version of the coherentist conception of truth might be the adequate notion of truth in mathematics or in the moral domain, but it seems utterly inadequate for contingent judgements. ${ }^{27}$ Lastly, superassertibility might provide the right model for truth in some evaluative domains or in mathematics, ${ }^{28}$ but it is inadequate for judgements concerning matters that are epistemically inaccessible to us-e.g. claims about the past for which no evidence has survived. Thus, although all these various notions of truth might provide a locally adequate model of truth, none of them gives us an adequate model of truth across all different domains.

My contention is that the monistic conception of the normative role of truth faces an analogous problem. If something along the lines of the variability conjecture described in sections III-VI is accurate, then it is easy to see why NAM is in trouble. It would in fact require thinkers to adopt a Procrustean attitude towards the negative assessment of a contrary view in the presence of a disagreement, regardless of the specific subject matter at issue. This would mean that, depending on which NP we take to characterise truth's normative function, some of the normative assessments described in the examples would be deemed inappropriate.

To illustrate: recall that alethic deontologism is the view according to which truth exerts only a deontic constraint over all judgements, cashed out in terms of 'ought', 'permissible', and 'impermissible'. Then this view would have problems accounting for the kind of normative assessment that seems appropriate in the domain of basic taste - and, arguably, in the domain

\footnotetext{
${ }^{26}$ See Lynch 2009: 34-36.

${ }^{27}$ A classical objection to coherentist accounts of truth can be found in Wright 1998.

${ }^{28}$ If, for example, you endorse a constructivist account of mathematics.
} 
of refined aesthetic matters as well. This is because such a view would say that false judgements are always impermissible and thus that a reactive attitude of rational condemnation to a contrary judgement would be always legitimate. ${ }^{29}$ But this is not what we would typically expect in situations of disagreement about basic taste or, more controversially, refined aesthetics.

Secondly, recall that alethic axiologism is the view according to which truth exerts only an axiological constraint over all judgements, cashed out in terms of 'valuable', 'good', and 'bad'. This view would have problems in accounting for the normative assessment typical of disagreement about basic taste—and, arguably, about fundamental moral matters. This is because such a view would say that false judgements are always bad, but not impermissible. However, this prediction seems inadequate for the basic taste case-because no substantive criticism is forthcoming - and also for the fundamental moral case-because a more substantive negative reaction would be expected.

Last, let us call alethic criterialism the view according to which truth exerts only a criterial constraint on judgement, cashed out in terms of 'correctness', 'fittingness', and 'incorrectness'. Since the kind of normative assessment of a contrary view predicted by this view would be paradigmatically weak, it would be inadequate to account for the kind of normative assessment that occurs in disagreements about fundamental moral issues and refined aesthetic matters - where some (more or less) substantive criticism to a contrary view would typically be deemed appropriate. The core of the normative scope problem is thus that none of these monistic views is adequate as a general view about truth's normative function. This puts considerable pressure on NAM.

\section{Normative Alethic Pluralism}

\footnotetext{
${ }^{29}$ It is important to highlight that the legitimacy of having a certain reactive attitude does not entail the legitimacy of expressing that attitude. There might be reasons (e.g. prudential, moral, or other kinds of contextual factors), that are independent of the norms governing judgements, that would make the expression of my reactive attitude inappropriate even though it would be legitimate for me to have such an attitude.
} 
In this and the following sections I introduce a pluralist framework for modelling the normative function(s) that truth exerts over judgements-Normative Alethic Pluralism - and show how this framework can be put to use to solve the scope problem. At the core of NAP are the following two theses:

Plurality There is more than one NP expressing truth's normative function on judgement. Variability Truth exerts a variable normative function on judgements from different areas of truth-apt discourse.

Plurality and Variability are meant to provide individually necessary and jointy sufficient conditions for NAP. They amount to the negation of Singularity and Uniformity respectively. Thus, according to NAP there is more than one correct NP expressing truth's normative function and, moreover, different areas of discourse are governed by different NPs.

NAP predicts that while the normative function of truth in one area of discourse might be expressed by a NP that encompasses the deontic dimension, in some other areas it might be expressed by a NP which encompasses the axiological dimension, and in other areas still it might be expressed by a NP which is exhausted by the criterial dimension - thus, without any deontic or axiological constraint. Interestingly, NAP leaves open the possibility of an area of discourse where truth is normatively inert, as it were, while still functioning as the aim of judgements in that area-and thus still exerting its teleological function. This means that it allows for a purely deflationary notion of truth (and falsity) that operates, locally, in some domains of discourse. ${ }^{30}$

In order to defend the cogency of NAP it is important to show that the criterial, the axiological, and the deontic dimensions enjoy a certain degree of normative independence from

\footnotetext{
30 The cogency of this option depends on whether we can make sense of a purely non-normative notion of truth. This is a debated issue among philosophers working on truth: see, for instance, Dummett 1959, Wright 1992 , Lynch 2009, Wrenn 2015. For some replies, see, e.g., Horwich 1998, Ferrari 2016b, Ferrari \& Moruzzi (forthcoming).
} 
each other. There are two ways in which these three dimensions can be normatively independent:

(IND 1) Criterial $\nRightarrow$ Axiological; Criterial $\nRightarrow$ Deontic; Axiological $\nRightarrow$ Deontic $^{31}$

(IND 2) Deontic $\nRightarrow$ Axiological; Deontic $\nRightarrow$ Criterial; Axiological $\nRightarrow$ Criterial

Arguing for both (IND 1) and (IND 2) would get us full normative independence, which means the strongest available form of NAP — call it strong NAP. Otherwise we could argue for only one direction of normative independence, and we would get two possible moderate forms of $\mathrm{NAP}$ - the first endorses (IND 1) without endorsing (IND 2), while the second endorses (IND 2) without endorsing (IND 1). ${ }^{32}$ Since the relevant direction of normative independence that we need in order to deal with the variability illustrated in the examples above is that expressed by (IND 1), in what follows I will argue for (IND 1) only, and I will remain silent on (IND 2). Moreover, to provide a full defence of the relevant moderate version of NAP we need an argument to show that (IND 2) fails-i.e. to show that we have at least one of the following direction of normative dependence:

(DEP 1) deontic $\Rightarrow$ axiological

(DEP 2) deontic $\Rightarrow$ criterial

(DEP 3) axiological $\Rightarrow$ criterial

Even though I believe that these normative dependences are plausible, I won't argue for them. What I will do in the next section is to defend a minimal version of NAP that is sufficient to solve the impasse generated by the normative version of Lynch's scope problem. Such a

\footnotetext{
31 ‘ $\nRightarrow$ 'should be read as: 'does not enforce...'.

${ }^{32}$ It is helpful to point out that the views that I call 'strong NAP' and 'moderate NAP' are quite different from the views that are often called 'strong alethic pluralism' and 'moderate alethic pluralism' in the alethic pluralism debate. Two remarks are especially relevant on this: first, that strong NAP doesn't entail strong alethic pluralism and, second, that moderate NAP doesn't entail moderate alethic pluralism.
} 
minimal version can then be elaborated either in the direction of strong NAP or in that of moderate NAP.

\section{Minimal Normative Alethic Pluralism}

To argue for minimal NAP we need to establish the following two claims: (i) that the presence of the criterial dimension by itself does not enforce either the axiological dimension or the deontic dimension and (ii) that the axiological dimension by itself does not enforce the deontic one.

Let's discuss the first claim first. The criterial dimension provides us with a standard for categorising judgements as correct or incorrect in accordance with the truth-value of their propositional content. There is an on-going debate about how to interpret the correctness norm and in what sense it is normative ${ }^{33}$ — whether in deontic terms, such as 'ought', or in what I call axiological terms, such as 'good', 'bad', and 'valuable'. I reject both interpretations. More precisely, I do not think that we are forced to adopt either interpretation. I follow $\mathrm{McHugh}^{34}$ here in understanding correctness as a distinct normative property in its own right, as neither deontic nor axiological. This thesis presupposes that the category of the normative should be conceived-as Thomson (2008) suggests-as more variegated than philosophers have traditionally sustained. Taking this on board, it may be argued that for a judgement to be correct is for it to have a normative property. But it is not correct because one ought to hold it, or because it would be good if one held it. Correctness is distinct from these other normative properties. For one thing, quite intuitively, while tipping might be the correct thing to do in a certain restaurant, provided that you have received adequate service, it's not something obligatory-thus refraining from tipping would be somehow incorrect, given the circumstances, but not impermissible. In this respect, the fact that it is correct to judge that $p$

\footnotetext{
${ }^{33}$ See Thomson 2008 for a discussion of the various kinds of normativity in relation to judgements.

${ }^{34}$ See McHugh 2014 and McHugh and Way 2015.
} 
does not imply that the subject ought to judge that $\mathrm{p}$. Moreover, something might be a correct thing to do, because, e.g., it is within your rights to do so, without this implying that it is also a valuable or good thing. The correct way of setting the table is to put the knife to the right of the plate and the fork on the opposite side, but intuitively there's nothing valuable in setting the table that way. ${ }^{35}$ In this respect, the criterial dimension does not entail the axiological one. In general, there should not be any deep difficulty in the thought that something could be correct without being valuable or obligatory, or incorrect without being disvaluable or impermissible. However, further inquiry is needed into what specific kind of sui generis normative notion correctness may be. ${ }^{36}$

Let us now turn to a discussion of the second normative independence claim-i.e. that the presence of the axiological dimension by itself does not enforce the presence of the deontic one. The axiological dimension tells us that it is, at least pro tanto, good, or valuable, to judge according to what is true, and that it is, at least pro tanto, bad, or disvaluable, to judge falsely. Again, how to understand the axiological dimension is a much-discussed topic. ${ }^{37}$ However, for the purpose of this paper we can leave the many, undoubtedly important, issues raised by that debate aside, and focus on the question of whether the axiological dimension per se entails the deontic dimension. There are reasons for thinking that it does not. As McHugh points out:

\footnotetext{
Something may be bad without its badness being a matter of anyone's having done anything they ought not have done, and without its being the case that there is anyone who ought to change it; some prospective state of affairs or
}

\footnotetext{
35 There is a similar, and familiar, contrast in the normative ethics debate: one might think that right actions are those that maximise utility but ask what is good about doing what is right.

${ }^{36}$ McHugh (2014: 177) suggests that we should understand correctness in terms of fittingness: "the attitude of belief sets truth as the standard that a proposition must meet in order for it to be a fit object of that attitude [...] For an attitude to be fitting is for it to have a normative property. But it is not fitting because you ought to hold it, or because you may hold it, or because it would be good if you held it. Fittingness, I maintain, is distinct from these other normative properties'.

${ }^{37}$ See, for instance, David 2005, Hazlett 2013, Kvanvig 2003, Lynch 2005, McHugh 2012.
} 
object may be good without its being the case that there is anyone who ought to produce it or bring it about. ${ }^{38}$

Thus, a false judgement may be bad or disvaluable without its badness or disvalue being a matter of someone having done anything they ought not to have done in judging so. Analogously, a true judgement may be good or valuable without its being the case that anyone ought to judge that way.

This thought can be substantiated by drawing a parallel between the moral case and the alethic case by means of the notions of supererogation and suberogation. In ethics, a supererogatory act is generally conceived as an act that goes beyond the call of duty and brings about a considerable moral good. As Chisholm puts it, supererogatory acts are "non-obligatory well-doing". 39 By contrast, following Chisholm's characterisation, we can say that suberogatory acts are “non-forbidden ill-doing”, or, in Driver's words 'suberogatory acts are bad to do, but not forbidden' ${ }^{40}$ Heroic acts are typical examples of the supererogatory: if I sacrifice my life in order to save a group of children who would otherwise die, this would be considered extremely good and valuable, but clearly non-obligatory-even if sacrificing my life is the only way to save those children. As an example of a suberogatory act, consider the following scenario. Julie has two perfectly healthy kidneys, but she refuses to donate one kidney to her sister Jill, who desperately needs one. Julie's refusal would be clearly suberogatory. Since Julie is under no obligation to donate her kidney, her refusal is not an impermissible thing to do. However, we would certainly consider such a refusal morally disvaluable. This reflects the widespread thought that it would be better if Julia donated her kidney to Jill.

What the categories of the supererogatory and suberogatory show is that there are acts that are intuitively morally optional but still open to an axiological assessment as to whether

\footnotetext{
${ }^{38}$ McHugh 2012: 10.

${ }^{39}$ Chisholm 1963: 3.

${ }^{40}$ Driver 1992: 286.
} 
they are good or bad. In the alethic case, we may say that an alethically supererogatory judgement — understood, remember, as a cognitive mental act —is a good judgement to make, because true, but not obligatory, while an alethically suberogatory judgement would be a judgement that is bad in that it violates the axiological dimension of the normative function of truth without thereby being a judgement that ought not to be performed. ${ }^{41}$

Unless we can find an argument to show that the concept of alethic suberogation is incoherent we should remain open to the possibility that in some areas of discourse there are cases of suberogatory judgements. This means that we should be wary of assuming that compliance with or violation of the axiological dimension automatically engenders compliance with or violation of the deontic dimension. As a consequence, we have the idea that truth's normative function in some domain may encompass the axiological dimension while at the same time being deontically silent.

No doubt, more need to be said to have an exhaustive picture of how these dimensions of truth's normative role are related to each other. However, I take the remarks that I have just offered as sufficient to establish the reasonableness of the partial normative independence claim (IND 1). This granted, we have at least the following four NPs governing truth's normative function:

(NP-1) Truth exerts a deontic constraint on judgements-perhaps together with both an axiological and a criterial constraint if we endorse (DEP 1 and DEP 2).

(NP-2) Truth exerts an axiological but not a deontic constraint on judgements-perhaps together with a criterial constraint if we endorse (DEP 3).

(NP-3) Truth exerts only a criterial constraint on judgements.

(NP-4) Truth exerts no normative constraint—-besides its teleological role.

\footnotetext{
${ }^{41}$ Turri first applied the category of the suberogatory to the case of the normativity of assertions, but differently, and with different aims; see Turri 2013.
} 


\section{Normative Alethic Pluralism and the Normative Scope Problem}

How does NAP help in dealing with the normative version of Lynch's scope problem as illustrated in section VII? The specific kind of negative normative assessment that I have in mind here can be understood by means of the notion of normative fault. The conjecture concerning the variable normative significance of disagreement discussed above can be reformulated as follows: the kind of fault that is attributable to someone holding a contrary view in the context of a disagreement might vary in relation to the subject matter of the disagreement. What does this variation in normative fault amount to? How should we model it? Once we take normative alethic pluralism on board, we are open to the idea that there is more than one dimension in which truth governs judgement. Correspondingly, we have a plurality of ways in which someone holding a view that is judged false might be said to be at fault. Thus, we have the following four categories of fault-attribution:

DEONTIC FAULT In judging not- $p$ the subject is judging in a way she ought not to.

AXIOLOGICAL FAULT In judging not-p the subject is doing something disvaluable.

CRITERIAL FAULT In judging not-p the subject is judging incorrectly.

NO FAULT

It is perfectly fine for the subject to judge the way she does.

As we saw in the previous section, the various dimensions of truth's normative profile are to a certain extent independent of each other. The various kinds of attributions of normative fault I have just introduced enjoy an analogous kind of independence. In particular, in line with the minimal version of NAP I am endorsing here, the three main categories of fault attribution listed above are independent of each other in the following way:

(IND 3) CRITERIAL FAULT $\nRightarrow$ AXIOLOGICAL FAULT; CRITERIAL FAULT $\nRightarrow$ DEONTIC FAULT; AXIOLOGICAL FAULT $\nRightarrow$ DEONTIC FAULT. 
Whether the other direction of independence also stands depends on whether we argue for a moderate or a strong version of NAP. I intend to remain neutral on this issue.

Thus, we might say that one's recognition that one disagrees with another person about certain subject matters licenses an attribution of criterial fault without licensing an attribution of axiological or deontic fault. Reflecting on the kind of negative assessment that seems appropriate in the disagreement between Julie and Jill about oysters, this could be the right prediction. Thus the (NP-3) model of the normativity of truth seems to be the adequate one for the domain of basic taste.

By contrast, disagreements about other matters might license an attribution of both criterial and axiological fault without licensing an attribution of deontic fault. And this might be what happens in typical cases of disagreement about refined aesthetic matters. Although it would seem appropriate for Julie to assess Jill's contrary but equally well informed view as somehow inferior — and thus to attribute axiological fault — it would seem inappropriate for Julie to assess Jill's contrary view as impermissible. Thus, no deontic fault seems to be forthcoming. In this respect, the (NP-2) model of the normativity of truth would be the adequate one for the domain of refined aesthetics.

Lastly, some disagreements might license an attribution of all these kinds of fault. This seems to be what happens in disagreements about fundamental moral issues where both parties would deem it appropriate to assess the opposite party's contrary view not only as incorrect and morally less valuable but also as one that ought not to be had. If this is right, then (NP-1) would be the right model for the normativity of truth in the fundamental moral domain.

An important question remains as to whether sense can be made of the (NP-4) model of the normativity of truth-i.e. whether we can have sensible disagreements involving judgements teleologically constrained by truth where no fault is involved. This ultimately 
depends on whether we can have a normatively inert truth property operating locally, in some areas of discourse. ${ }^{42}$

\section{Conclusions}

I have discussed what I take to be an interesting variability in the normative significance of disagreement and I have suggested that such variability requires some flexibility in the normative function that truth exerts in different areas of discourse. Because a monistic view on truth's normative function —-what I have called normative alethic monism — forces us to adopt a Procrustean attitude towards the normative significance of disagreement, it is inadequate as a general model of the normativity of truth. I have argued for this by presenting a variation of what is known in the truth pluralism literature as the scope problem.

I have outlined a pluralist framework for understanding the normativity of truthnormative alethic pluralism - that promises to score better than normative alethic monism in addressing the variability in the normative significance of disagreement discussed above. The key point of my proposal is to understand variation in normative fault by looking at which dimensions of truth's normative profile operate in a given domain of discourse. Once we adopt this pluralistic stance towards the normativity of truth, we obtain a framew ork which adequately models the variability in the normative significance of disagreement across different areas of discourse. In other words, NAP provides us with all the necessary tools for addressing the normative version of the scope problem. ${ }^{43}$

\footnotetext{
${ }^{42}$ Ferrari \& Moruzzi (forthcoming).

${ }^{43}$ This paper has enormously benefitted from discussions with Elke Brendel, Matthew Chrisman, Massimo Dell'Utri, Douglas Edwards, Matti Eklund, Andreas Fjellstad, Patrick Greenough, Thomas Grundmann, Paul Horwich, Nathan Kellen, Michael Lynch, Giacomo Melis, Anne Meylan, Moritz Müller, Carol Rovane, Andrea Sereni, Erik Stei, Elena Tassoni, Joe Ulatowski, Giorgio Volpe, Jack Woods, Chase Wrenn, Cory Wright, Jeremy Wyatt, Luca Zanetti, Dan Zeman. Special thanks are due to Carrie Ichikawa Jenkins, Sebastiano Moruzzi, Nikolaj Pedersen, Eva Picardi and Crispin Wright. Moreover, I would like to acknowledge the generous support of the Deutsche Forschungsgemeinschaft (DFG - BR 1978/3-1) for sponsoring my postdoctoral fellowship at the University of Bonn.
} 


\section{References:}

Chan, T. 2013 (ed.), The Aim of Belief (Oxford: Oxford University Press)

Chisholm, R. 1963 'Supererogation and Offense: A Conceptual Scheme for Ethics', in Ratio, $5: 1-14$

Chrisman, M. 2016 'Epistemic normativity and cognitive agency', Noûs, doi:10.1111/nous.12184

David, M. 2005 'On Truth is Good', in Philosophical Books 46(4): 292-301

Driver, J. 1992 'The Suberogatory', in Australasian Journal of Philosophy 70(3): 286-295

Dummett, M. 1959 'Truth', in Proceeding of the Aristotelian Society 59: 141-162

Ferrari, F. (2016a) 'Disagreement about Taste and Alethic Suberogation', The Philosophical Quarterly, 66(264): 516-35.

Ferrari, F. (2016b) ‘The Value of Minimalist Truth', Synthese (DOI 10.1007/s11229-016-1207-

9)

Ferrari, F. \& Moruzzi, S. (forthcoming) 'Ecumenical Alethic Pluralism', forthcoming in The Canadian Journal of Philosophy.

Ferrari, F. \& Wright C. (2017) 'Talking with Vultures', Mind 126(503): 911-36.

Field, H. 1994 'Deflationist views of meaning and content', in Mind 103(411): 249-85

Gibbard, A. 2005 'Truth and Correct Belief’, in Philosophical Issues 15: 338-350

Hazlett, A. 2013 A Luxury of the Understanding: On the Value of True Belief (Oxford: Oxford University Press)

Horwich, P. 1998 Truth (2 ${ }^{\text {nd }}$ Edition) (Oxford: Oxford University Press)

Horwich, P. 2013 'Belief-Truth Norms', in T. Chan (ed.): 17-31

James, W. 1975 Pragmatism and the Meaning of Truth (Cambridge MA.: Harvard University Press) 
Kvanvig, J. 2003 The Value of Knowledge and the Pursuit of Understanding, (Cambridge:

Cambridge University Press)

Loewer, B. 1993 'The Value of Truth', in Philosophical Issues 4: 265-280

Lynch, M. 2005 True to Life (Cambridge Ma.: The MIT Press)

Lynch, M. 2009 Truth as One and Many (Oxford: Oxford University Press)

Lynch, M. 2013 'Three questions for truth pluralism', in Pedersen and Wright (2013): 21-41

MacFarlane, J. 2014 Assessment Sensitivity: Relative Truth and its Applications (Oxford:

Oxford University Press)

McHugh, C. 2012 'The Truth Norm of Belief’, in Pacific Philosophical Quarterly 93: 8-30

McHugh, C. 2014 'Fitting Belief', in Proceedings of the Aristotelian Society 114(2): 167-187

McHugh, C. and Way, J. 2015 'Fittingness First', in Ethics 126(3): 575-606

Pedersen, N. and Wright, C. 2013 (eds.) Truth and Pluralism: Current Debates, (Oxford: Oxford University Press)

Shah, N. and Velleman, D. 2005 'Doxastic Deliberation', in Philosophical Review 114(4): $497-$ 534

Sosa, E. 2015 Judgement and Agency, Oxford: Oxford University Press.

Strawson, P. 1962 'Freedom and Resentment' in Proceedings of the British Academy, 48: 125

Thomson, J.J. 2008 Normativity (La Salle Ill.: Open Court)

Turri, J. 2013 'Knowledge and Suberogatory Assertion, in Philosophical Studies, 3: 1-11

Wedgwood, R. 2007 The Nature of Normativity (Oxford: Oxford University Press)

Williams, B. 1973 Problems of the Self (Cambridge: Cambridge University Press)

Williams, R. 2012 "Indeterminacy and Normative Silence”, Analysis 72(2): 217-25.

Williamson, T. 2000 Knowledge and its Limits (Oxford: Oxford University Press)

Wrenn, C. 2015 Truth (Cambridge: Polity Press) 
Wright, C. 1992 Truth and Objectivity (Cambridge Ma.: Harvard University Press)

Wright, C. 1998 'Truth: A Traditional Debate Reviewed', in Canadian Journal of Philosophy, Supplementary Volume: 31-74.

Wyatt, J. (2018) 'Absolutely tasty: an examination of predicates of personal taste and faultless disagreement', Inquiry, 61 (3): 252-80. 